\title{
THE ELECTRON ACCELERATOR INSTALLATIONS WITH LOCAL SHIELDING FOR APPLIED PURPOSES
}

\author{
G. Batskikh, G. Mamaev, A. Mischenko, V. Pirozhenko \\ MRTI RAS, Moscow
}

\section{Abstract}

The use of the local shielding for electron accelerators considerably extends the capabilities of its application for various purposes, because they can operate in ordinary working rooms. So there is no need to construct special buildings with cumbersome shielding. Since the cost of local shielding depends on its sizes, the compact accelerators have developed in the MRTI.

Three accelerating installations are presented in the report: $8 \mathrm{MeV}$ installation for custom inspection of large cargo containers, $5 \mathrm{MeV}$ installation for sterilization of medical instruments, infectious waste, conservation food etc., and $200 \mathrm{keV}$ installation for industrial techniques.

\section{INTRODUCTION}

The electron accelerators are widely used in industry and medicine. However, radiation danger appears in its operation. It requires application of biological radiation shielding. Two versions of radiation shielding are possible: local shielding, i.e. location of accelerators and basic technical equipment into the special container opaque to radiation arising in accelerator operation, or construction of a special room with shielded walls. The application of local shielding in many cases appears cheaper than construction of special rooms with thick concrete walls. Besides accelerating installation with local shielding appears compact and can be transportable. As a rule, the local shielding until recently was applied for accelerating installations for the energy up to $800 \mathrm{keV}$. In MRTI the installations with local shielding for the energy up to $8 \mathrm{MeV}$ were created.

\section{CUSTOM INSPECTION LINAC}

The cost of biological shielding depends on the sizes of the accelerator, therefore compact linear electron accelerators (Fig. 1) were developed [1]. Its parameters are listed in Table 1.

The accelerating structure represents a set of coupled cavities (Fig. 2) $\pi / 2$ standing wave excited.

Coupling cells located on axis between accelerating cells. The form of RF field in accelerating cavities provides not only acceleration, but also focussing of the beam. It allows to do without magnetic solenoids and to reduce the transverse sizes of the accelerator. Magnetrons
MI-456 with pulse power of 2,5 MW and mean power of $4 \mathrm{~kW}$ are used for an accelerating field excitation.

Table 1. Compact electron linac parameters.

\begin{tabular}{|c|c|c|}
\hline 1. Energy of accelerated particles, $\mathrm{MeV}$ & 5 & 8 \\
\hline 2. Number of accelerating cells & 11 & 17 \\
\hline 3. Accelerator length, $\mathrm{cm}$ & 64 & 99 \\
\hline 4. Accelerator diameter, $\mathrm{cm}$ & \multicolumn{2}{|c|}{13} \\
\hline 5. Operational frequency, $\mathrm{MHz}$ & \multicolumn{2}{|c|}{2797} \\
\hline 6. Pulse current, A & 0,28 & 0,12 \\
\hline 7. RF pulse duration $\tau, \mu \mathrm{s}$ & \multicolumn{2}{|c|}{$5,5-11$} \\
\hline 8. Pulse duration of beam current, $\mu \mathrm{s}$ & \multicolumn{2}{|c|}{$5-10,5$} \\
\hline 9. Repetition rate, $\mathrm{Hz}, \quad \begin{aligned} \text { at } \tau & =5,5 \mu \mathrm{s} \\
\tau & =11 \mu \mathrm{s}\end{aligned}$ & \multicolumn{2}{|c|}{$\begin{array}{l}50-300 \\
50-150\end{array}$} \\
\hline 10. Beam diameter, mm & \multicolumn{2}{|c|}{2} \\
\hline 11. Mean power, $\mathrm{kW}$ & 2 & 1,4 \\
\hline 12. Power consumption, $\mathrm{kW}$ & \multicolumn{2}{|c|}{15} \\
\hline
\end{tabular}

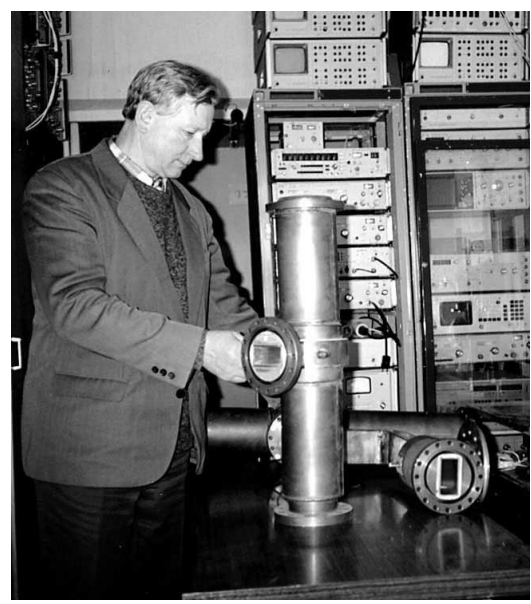

Figure 1: $8 \mathrm{MeV}$ compact electron linac.

The accelerator with energy of $8 \mathrm{MeV}$ is used in the installation for the X-ray control of auto vans, transport containers, lorries and etc. at customs inspection of cargoes (Fig. 3).

\footnotetext{
${ }^{*}$ Works are supported in part by State Custom Committee of Russia, BioSteril Technology, Inc. and MRTI RAS.
} 


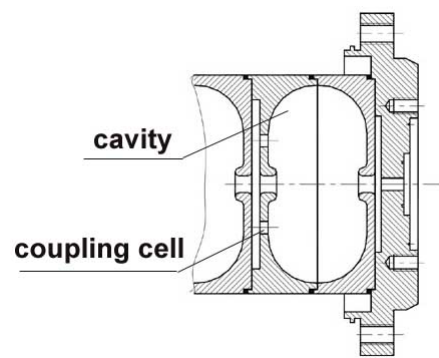

Figure 2: Accelerating structure
$8 \mathrm{MeV}$ accelerator provides depth of steel $\mathrm{X}$-raying up to $340 \mathrm{~mm}$, i.e. we can see the image of subjects behind a steel barrier $34 \mathrm{~cm}$ thick. Productivity of installation is up to 15 auto vans per hour. The application of accelerator with local shielding decreases many-fold a level of radiation in operating rooms. It allows to use for installation accommodation the modular facilitated building designs, that makes civil work cheaper and, basically, enables if necessary quickly reinstall it on a new place.

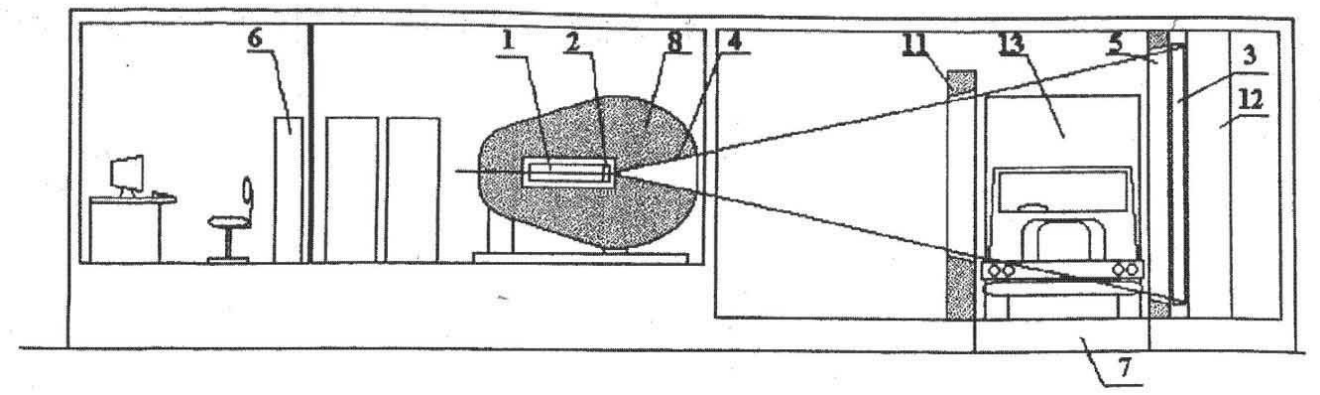

Figure 3: Installation for customs inspection of auto vans.

1 - accelerator; 2 - converter, 3 - local shielding; 4 - auto vane

\section{ACCELERATOR FOR STERILIZATION}

The accelerator with the energy of $5 \mathrm{MeV}$ is applied in the installation for radiation sterilization of medical instruments and medical infection wastes in clinics and hospitals, sterilization of medical products at their production, sterilization of foods for essential increase of its storage time, and also suppression of microorganisms dangerous for human health. Installation view is shown in Fig. 4. The rotor transporter is applied in this case. There

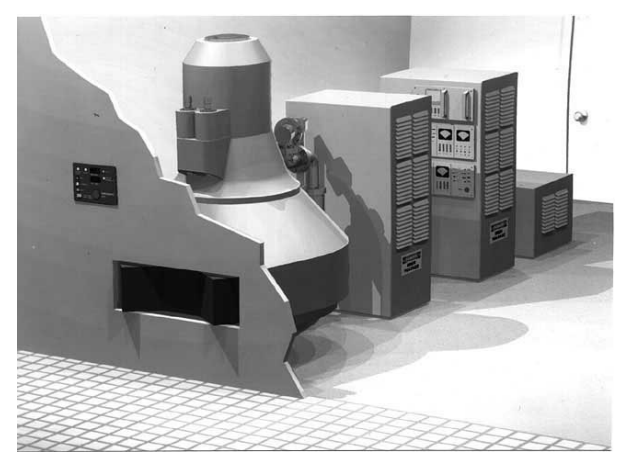

Figure 4: Installation for X-ray sterilization.

is a version with the linear transporter. Productivity of the installation is up to $200 \mathrm{~kg}$ of sterilized materials per hour. A design of shielding completely eliminates a capability of emergencies connected with radiation danger that allows to place the installation in any working room. The installation is transportable, since its weight does not exceed $20 \mathrm{t}$.

\section{INDUSTRIAL ACCELERATOR}

Principe of local shielding was used for design of smallscale accelerator with the energy up to $180 \mathrm{keV}$ [2].

Installation uses accelerated electron beam for material processing, for surface X-ray sterilization in clinics and for other purposes. The general external appearance of this installation is presented in Fig. 5.

Electron beam is generated by seal off electron gun. Gun is energized by high-voltage pulse transformer.

These units are combined in unified compact design. Radiation shielding makes it possible to use this installation in any room. Installation parameters are listed in Table 2.

Table 2. General parameters of installations.

\begin{tabular}{|l|c|}
\hline Electron energy (regulated), $\mathrm{keV}$ & $100-200$ \\
\hline Repetition rate, $\mathrm{Hz}$ & 200 \\
\hline $\begin{array}{l}\text { Max. pulse power of extracted beam, } \\
\mathrm{kW}\end{array}$ & 300 \\
\hline Irradiation area, mm & $200 \times 100$ \\
\hline $\begin{array}{l}\text { Max. pulse dose rate of electron beam, } \\
\text { kGy/s }\end{array}$ & $5 \cdot 10^{4}$ \\
\hline Power consumed, $\mathrm{kW}$ & 2 \\
\hline Overall dimensions (w/o computer), $\mathrm{m}$ & $2 \times 0.7 \times 0.7$ \\
\hline
\end{tabular}




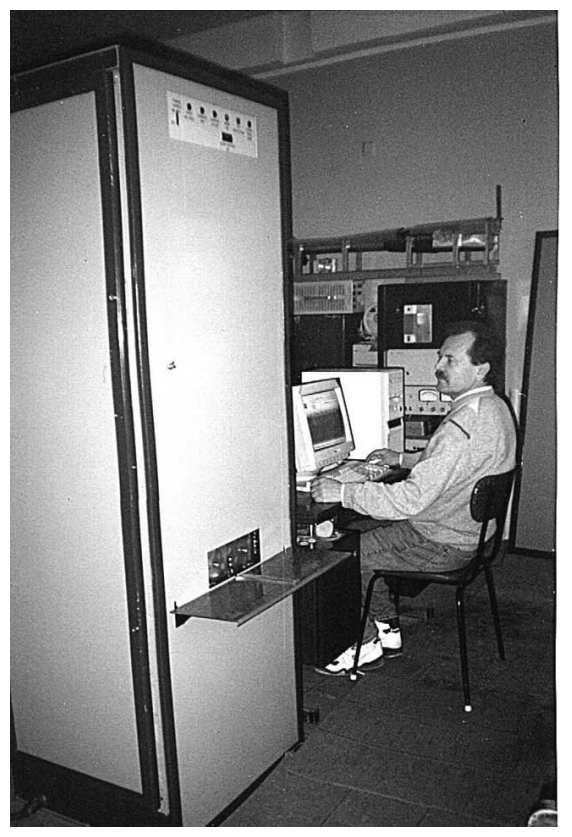

Figure 5: Installation for material processing by electron beam.

Shielding consists of two envelopes. The first (internal) shell of the shielding covers the electron gun and irradiation zone. The second (external) one covers the electron gun, irradiation zone and high-voltage transformer. All panels are $3 \mathrm{~mm}$ thick steel sheets to which $5 \mathrm{~mm}$ thick lead sheets are riveted, the rivets being made of tin, that is also material with good radiation attenuation.

\section{REFERENCES}

[1] A.A.Zavetsev, Yu.D.Petrov, MRTI RAS. "Standing Wave Linac Accelerating Structure for Technology Purposes", London, 1994, EPAC-94, p.2173.

[2] S.Krylov, T.Latypov, G.Mamaev， S.Mamaev， V.Pirozhenko, S.Poutchkov, I.Tenyakov, MRTI RAS, A.Korolev, K.Simonov, Istok. "Compact Pulse Electron Accelerator for Radiation Processing of Materials", this Conference. 